\title{
O PAPEL DO INTÉRPRETE INDÍGENA NA APRENDIZAGEM DA MATEMÁTICA ESCOLAR
}

\author{
THE ROLE OF INDIGENOUS INTERPRETER \\ IN THE MATHEMATICS LEARNING
}

Karynna Silva Oliveira*

\section{Resumo}

Este artigo consiste em um relato de experiência que traz os resultados de uma atividade de campo realizada junto aos educadores e educandos indígenas da escola urbana de Aragarças, Goiás. O trabalho desenvolvido teve como finalidade dialogar e refletir sobre o papel do intérprete indígena e dos materiais manipuláveis na aprendizagem da Matemática escolar. A elaboração e desenvolvimento das atividades foram fundamentados em referências que tratam da Educação escolar Indígena, Etnomatemática, Educação Matemática Crítica, em reflexões sobre o desenvolvimento profissional do professor de Matemática - mais especialmente, no que tange à reflexão sobre a prática e o papel dos materiais manipuláveis na aprendizagem de Matemática. Em relação à análise, tem-se o perfil qualitativo e metodologia fenomenológica. A atividade abordada se situa em oficina sobre "O Segredo dos Números", um material manipulável, objetivando facilitar a transposição da matemática concreta para a abstrata.

Palavras-chave: Educação Matemática, Professor Intérprete Indígena, Materiais Manipuláveis.

\section{Introdução}

A escolha por investigar o papel do intérprete e da aprendizagem dos indigenas nas escolas urbanas veio das experiências e vivências junto às escolas públicas de Barra do Garças, Mato Grosso, e Aragarças, Goíás, ocorreu durante o meu curso de licenciatura. Ao ingressar na Universi-

*Licenciada em Matemática pela Universidade Federal do Mato Grosso (UFMT).

E-mail: karynasilva@ hotmail.com 
O papel do intérprete indígena na aprendizagem da Matemática Escolar

dade Federal de Mato Grosso - UFMT, tive oportunidade de fazer parte do Programa Institucional de Bolsas de Iniciação à Docência (PIBID), a partir do qual adquiri vivências e experiências escolares mais próximas das atividades docentes, assim como a realidade vivida por eles.

Nestas idas e vindas, eu me deparei com alguns educandos indígenas que frequentavam as escolas urbanas da região. Percebi que eles eram muito tímidos, reservados e sempre se sentavam no fundo da sala. Minha impressão era que tinham dificuldades de nos compreender e, por isso, eram deixados de lado por todos - colegas, educadores, diretores e governo. Daí, minha angústia, pois percebi que sentar no fundo era uma reação de defesa de quem estava sendo excluído dos processos de aprendizagem. Notei também que eles tinham dificuldades com os conteúdos, especialmente de Matemática, mas não havia ninguém para acompanhálos e isto me fez refletir sobre qual é o sentido de uma escola inclusiva.

O segundo contato com eles foi durante o Estágio Supervisionado, que realizei nas escolas do municipio de Aragarças. Nas observações sobre a realidade escolar, tive outras percepções e curiosidades sobre os estudantes e educadores indígenas. Pude notar, por exemplo, que a presença deles em escolas urbanas agora é maior, porém não há somente educandos, também há os educadores auxiliares - intérpretes indigenas. São educadores que fazem parte de um projeto, que se traduz na tentativa de auxiliar os educandos indígenas em sala de aula, o que me trouxe algumas indagações acerca de: quem são estes educadores, como é seu trabalho e como a presença deles interfere no ensino aprendizagem dos educandos?

Constatei também que eles - os estudantes indígenas - estão chegando à segunda etapa do Ensino Fundamental sem saber falar, escrever e compreender o idioma português, o que remeteu a uma reflexão acerca das determinações da Lei $n^{\circ} 4.024 / 61$, que no seu artigo $78^{\circ}$ e $79^{\circ}$ diz ser "dever do Estado o oferecimento de uma educação escolar bilíngue e intercultural que fortaleça as práticas socioculturais e a lingua materna de cada comunidade indígena." Determinação também descrita na Cons- 
O papel do intérprete indígena na aprendizagem da Matemática Escolar

tituição Federal, de 1988, e no Decreto $n^{\circ}$ 6.861/2009, que dispõe sobre a Educação Escolar Indígena, em cujo artigo $3^{\circ}$ determina que "será reconhecida às escolas indigenas a condição de escolas com normas próprias e diretrizes curriculares específicas, voltadas ao ensino intercultural e bilingue ou multilingüe." (BRASIL, 2009).

Entretanto, há uma aparente omissão do que está disposto na legislação sobre a presença dos indigenas nas escolas urbanas. Este fato me remeteu a um questionamento sobre a presença dos educandos indígenas nas escolas da região do Médio Araguaia, o que parece caracterizar um contexto específico. Outro questionamento que aflorou foi: se estes indios ${ }^{1}$, que frequentam as escolas urbanas, estão chegando aos quatro últimos anos do Ensino Fundamental sem saber ler, escrever e falar a língua portuguesa, então: como eles acompanham o desenvolvimento da turma, especialmente no diz respeito à linguagem da matemática escolar?

Notei também que, nessa segunda escola, eles - os indios - não se sentavam no fundo da sala; porém, isto não significa que estivessem incluídos nos processos de aprendizagem. Aparentemente, eles apenas conseguem se relacionar mais facilmente com outros educandos. Estaseria uma mudança motivada pela presença dos intérpretes?

Durante a disciplina de Estágio Supervisionado III, tive a oportunidade de ministrar aulas para dois educandos indígenas - um deles já sabia escrever e falar um pouco a língua portuguesa e, o outro, ainda tinha muitas dificuldades por não saber se expressar e nem escrever em português. Em uma das aulas, levei um material chamado "O segredo dos Números", um material manipulável (concreto) elaborado por Esther Pillar Grossi (2006, apud FIETZ e MARTINS, 2010) que auxilia em uma melhor compreensão da operação de multiplicação de números naturais. Ao fim dessa aula, uma professora intérprete (indígena) me disse: é isso que precisamos! Enxergar, ver o que está acontecendo.

${ }^{1}$ Este trabalho optou por termo Índio seguindo a linha de raciocínio do Daniel Munduruku, da etnia Munduruku (https://www.youtube.com/watch?v=s39FxY3JziE) 
O papel do intérprete indígena na aprendizagem da Matemática Escolar

Através desta observação da intérprete, tive a motivação necessária para desenvolver um trabalho por meio do qual procurei saber: como os materiais manipuláveis podem ajudar no desempenho de educandos indigenas na disciplina de Matemática? Uma preliminar das respostas demonstrou haver potencial dessa ferramenta para a aprendizagem desses educandos. Vale ressaltar que as respostas preliminares deste trabalho foram publicadas em Oliveira (2019) em um evento científico realizado em Cuiabá, Mato Grosso.

Todo esse conjunto de percepções, angústias e questionamentos me motivou a pensar sobre papel do professor de Matemática e me fizeram buscar informações sobre a Educação Matemática Crítica - EMC, a Etnomatemática e sobre as possibilidades dos materiais manipuláveis na aprendizagem da disciplina, para refletir melhor sobre qual é o papel do educador matemático que atua junto à educação indígena. As angústias e questionamentos estão sintetizados na indagação central: qual o papel do intérprete indígena no processo de aprendizagem da matemática?

\section{Da prática à teoria: a trajetória rumo à pesquisa}

Em 2015, as escolas do município de Aragarças, no Estado de Goiás, iniciaram uma proposta de acompanhamento aos indigenas que migravam para a cidade em busca de educação escolar. Segundo a coordenadora da Educação no Campo, Indigena e Quilombola, Valéria Cavalcante da Silva Souza (2017), a iniciativa se deu através do pedido de uma gestora da rede Estadual para a Secretaria de Estado de EducaçãoSEDUCE/GO. Uma demanda que começou a ser atendida com quatro educadores intérpretes da etnia A'uwe-Xavante para atender seis educandos, em três unidades de ensino regular. "Atualmente, existem noventa e seis educadores intérpretes indígenas espalhados em todo o Estado de Goiás." (SOUZA, 2017).

Os educadores indígenas atuam "no letramento em que envolve leitura, oralidade, produção e interpretação no contexto cultural do estudante no espaço social de vivência e da comunidade." (SOUZA, 2017, p. 
O papel do intérprete indígena na aprendizagem da Matemática Escolar

35). Durante o meu estágio supervisionado presencie o trabalho desses educadores e surgiu o meu interesse em verificar como poderia ser a atuação dos mesmos no ensino de Matemática.

A coordenadora Valéria Souza, em um depoimento, afirmou que mesmo com a presença desses educadores intérpretes há muita "dificuldade com a disciplina de matemática, pois os professores não tiveram acesso aos estudos da etnomatemática" Essa afirmação foi o ponto inicial para que eu pudesse elaborar um projeto de formação para estes educadores que atuam na rede, tendo como ferramenta principal os materiais manipuláveis, uma vez que minha vivência indiciou que esses materiais podem colaborar para a aprendizagem dos educandos indígenas.

Esse conjunto de fatos me fez perceber que era preciso retomar a reflexão do ponto inicial, voltar ao momento que me permitiu olhar para os indigenas das escolas de Aragarças sob outra perspectiva. Mais precisamente, do momento que percebi a presença e a realidade vivida por eles na sala de aula.

O primeiro momento se deu durante o estágio supervisionado, ao perceber a presença de alguns educandos indígenas nas escolas urbanas. Foi um estranhamento o fato de eles estarem frequentando os anos finais do Ensino Fundamental sem falar a língua portuguesa. Naquela época, tive uma primeira impressão sobre o que poderia estar acontecendo nas escolas indigenas, onde o ensino bilíngue é oferecido para os educandos e é reconhecido por lei. Pude constatar que eles se sentem reprimidos e deslocados nas salas de aula. Foi quando senti que não só precisava, mas também poderia colaborar.

Um segundo momento, ocorreu em meio aos trabalhos do estágio, quando fui ministrar minha primeira aula, em uma sala composta por educandos indigenas e não-indigenas. Vale lembrar que, na universidade, tive algumas orientações relacionadas a como planejar uma aula, na qual, a construção do conhecimento pudesse alcançar os diferentes grupos étnicos que ali estavam. Nesta oportunidade, fui surpreendida com a 
O papel do intérprete indígena na aprendizagem da Matemática Escolar

presença dos educadores intérpretes indígenas, especialmente com a presença da professora Maria de Fátima Tsitedze, uma pessoa que ajudou muito na execução da atividade, com a qual tinha tido um contato recente na universidade.

Tratava-se de um material concreto que auxilia na compreensão da multiplicação, dos múltiplos de um número natural, dos divisores de um número natural, dos critérios de divisibilidades, fatoração e potenciação. Tomei, então, a decisão de levar "O Segredo dos Números", um material manipulável que poderia ajudar os educandos a visualizarem como ocorre a formação dos números por meio da multiplicação e assim auxiliá-los na construção dos conceitos propostos. Ao fim da aula a educadora intérprete indigena - a Professora Tsitedze declarou: "é isso que precisamos ver o que está acontecendo". Foi a partir dela que surgiram minhas percepções, curiosidades e motivações em entender o papel dos materiais manipuláveis como ferramenta de ensino e a importância desses educadores como mediadores da aprendizagem dos educandos indígenas, dentro das escolas urbanas.

O passo seguinte foi buscar uma maior compreensão da Educação Escolar Indigena para saber como estes educadores e educandos chegaram às escolas urbanas. Neste sentido, a cronologia adotada por Ferreira e Lopes (2001) na Obra "A educação escolar indigena: um diagnóstico crítico da situação no Brasil” foi fundamental para perceber o quanto este povo tem lutado contra o processo de aculturação - provocado pelos jesuitas e pelo Estado ao longo de quinhentos anos - para ter suas identidades reafirmadas. E, também existe a luta dos povos indigenas por uma educação escolar de qualidade, hoje garantida por lei, mas que não é cumprida. Isso, dentre outras circunstâncias, faz com que, em muitos casos, famílias inteiras se desloquem das comunidades indígenas para a cidade em busca de uma educação escolar formal.

Essas constatações me fizeram entender que, diante de tanta diversidade na sala de aula, os educadores são obrigados a sair de sua zona de conforto à procura de métodos e atividades diferenciadas que propor- 
O papel do intérprete indígena na aprendizagem da Matemática Escolar

cionem uma aprendizagem mais significativa para todos os educandos, e que ele sempre tem que estar em busca de conhecimento para aulas mais dinâmica, atrativas e criativas, sendo ativo em busca da formação continuada.

Sinteticamente, a vivência nesse espaço escolar diferenciado foi préponderante não somente para a atitude de adotar os materiais manipuláveis como tema de estudo, mas também para a decisão de entender um pouco mais sobre o papel do professor intérprete indigena nas escolas de Aragarças. Entretanto, para melhor compreensão da proposta considero necessário reiterar alguns pontos já definidos ao longo do estudo, mas que são relevantes à organização do mesmo.

No tocante à minha atuação profissional, busquei me fundamentar na proposição de Ponte (1994), um estudo que diz respeito ao desenvolvimento profissional do professor de Matemática. Nele, o autor defende que a formação inicial, como regra, não é suficiente para a prática cotidiana competente. Por isso, a incorporação da prática de pesquisa e da formação continuada deve fazer parte desse desenvolvimento, mais especificamente no que diz respeito à constante necessidade de reflexão sobre a prática que, neste caso, envolve a aprendizagem dos indigenas $A^{\prime} u w \bar{e}$ Xavante que frequentam as escolas urbanas da no Médio Araguaia.

Um estudo reiterou a necessidade de aprofundar os conhecimentos teóricos e metodológicos sobre os caminhos contemporâneos para levar a aprendizagem significativa da Matemática. Vale ressaltar que a consequente busca me conduziu aos princípios da Educação Etnomatemática, Educação Matemática Crítica e no uso dos Materiais Manipuláveis.

Como aprendizado da Etnomatemática, eu trouxe a compreensão de que cada grupo cultural tem suas maneiras de produzir conhecimento a partir das necessidades e percepções sobre a realidade, consequentemente, cada grupo tem seu modo de procurar soluções para problemas do cotidiano, tendo em vista que cada etnia, povo ou grupo responder às questões cotidianas, de acordo com seu olhar sobre o mundo. E, neste 
O papel do intérprete indígena na aprendizagem da Matemática Escolar

sentido, a etnomatemática orienta e inspira o educador a estabelecer pontes entre a matemática escolar e os conhecimentos trazidos e desenvolvidos pelos educandos de suas experiências e vivência, neste caso em especial, o modo dos $A^{\prime} u w \bar{e}$-Xavantes lidarem com a realidade. Vale ressaltar que a pretensão deste estudo em caminhar no sentido de compreender como os conhecimentos produzidos, a partir do programa, podem auxiliar na aprendizagem da matemática escolar dos indígenas, já que a presença deles é cada dia maior nas escolas urbanas da região. Sendo assim, com auxílio dos fundamentos da etnomatemática, entre outros, procurei compreender a maneira como os educandos indígenas "geram e sistematizam seus saberes/conhecimentos matemáticos na busca de soluções de problemas" (SILVA, 2019) impostos pela Educação Escolar.

Da Educação Matemática Crítica, o principal fundamento consiste na proposição que instiga os educadores de matemática a tomarem posicionamentos crítico e político sobre a educação, o ensino e o uso do conhecimento matemático, ou seja, a Educação Matemática Crítica propõe aos educadores desenvolverem um trabalho no sentido de propor uma matemática que sirva à cidadania. $\mathrm{E}$, no que diz respeito, mais especificamente, à atividade foco - O Segredo dos Números (jogo elaborado por Esther Pillar Grossi, em 1986, e refeito com algumas adaptações em 2012). Vale relatar que foi uma atividade desenvolvida, pela primeira vez, junto a um grupo de educandos indígenas, tendo como objetivo facilitar a transposição da matemática concreta para a abstrata.

\section{Desenvolvimento da pesquisa}

A segunda etapa desse estudo pode ser sintetizada como uma análise mais aprofundada do estudo Oliveira (2019), na qual foi desenvolvida uma atividade no Estágio Supervisionado III. Naquele momento, o mesmo foi interpretado como hermenêutico fenomenológico, por se valer de técnicas e instrumentos qualitativos de análise, tais como: entrevistas, depoimentos, vivências, narrativas, revisões bibliográficas, histórias de vida e análise do discurso. Entendendo também que estes recursos possibilitam investigar as situações vividas pelos sujeitos envolvidos. Ainda na 
O papel do intérprete indígena na aprendizagem da Matemática Escolar

perspectiva de construção da análise, vale ressaltar que o estudo apresentou também características naturalista de análise, pelo fato de ele impor ao pesquisador a necessidade de frequentar os locais onde os fenômenos ocorrem.

De outro ponto de vista, pode-se afirmar que estudos desta natureza implicam na procura de respostas acerca de instrumentos, dinâmicas, atitudes, motivações e comportamentos dos sujeitos - neste caso o encontro dos educandos com os educadores indigenas e o material manipulável - perante a utilização de ferramenta de contemporâneas de ensino. Por esta razão, optei por adotar parcialmente a atitude metodológica de natureza interpretativa e descritiva, visto que segundo Bogdan e Biklen (1994, apud CAMACHO, 2012), uma abordagem deste tipo é composta por 5 particularidades:

(1) a fonte direta dos dados é o ambiente natural e o investigador é o principal agente na recolha desses mesmos dados;

(2) os dados que o investigador recolhe são essencialmente de carácter descritivo;

(3) os investigadores que utilizam metodologias qualitativas interessam-se mais pelo processo em si do que propriamente pelos resultados;

(4) a análise dos dados é feita de forma indutiva;

(5) o investigador interessa-se, acima de tudo, por tentar compreender o significado que os participantes atribuem às suas experiências

Sendo assim, procurei constituir a análise da atividade, que usou como instrumento o jogo O Segredo dos Números, tomando como referência, alguns dos orientadores indicados pelo autor diante a investigação que tem entre seus objetivos: descobrir a composição dos números através do material concreto e também, compreender os conceitos de Múltiplos, Divisores e Números Primos. 


\subsection{Atividade Desenvolvida: primeira etapa}

A atividade a ser analisada, neste estudo, foi desenvolvida no município de Aragarças, Goiás, na Escola Estadual Mercedes Zétola. A escolha da unidade se deu por conta da familiaridade adquirida no periodo do Estágio Supervisionado, onde realizei observações que instigaram a busca por conhecimento sobre os educandos indígenas, também por ter participado de alguns projetos de extensões no local.

No tocante a atividade em análise, foi ministrada uma oficina na biblioteca da escola para quatro estudantes indigenas (o objetivo era verificar se o uso dos materiais manipuláveis poderia contribuir na aprendizagem dos mesmos) - dois do sexto ano, um do sétimo e um do oitavo participaram, quanto a não participação do nono ano, se justifica por estarem tendo "aulão" (um estudo que a escola fornece para preparar os educandos para prova do governo).

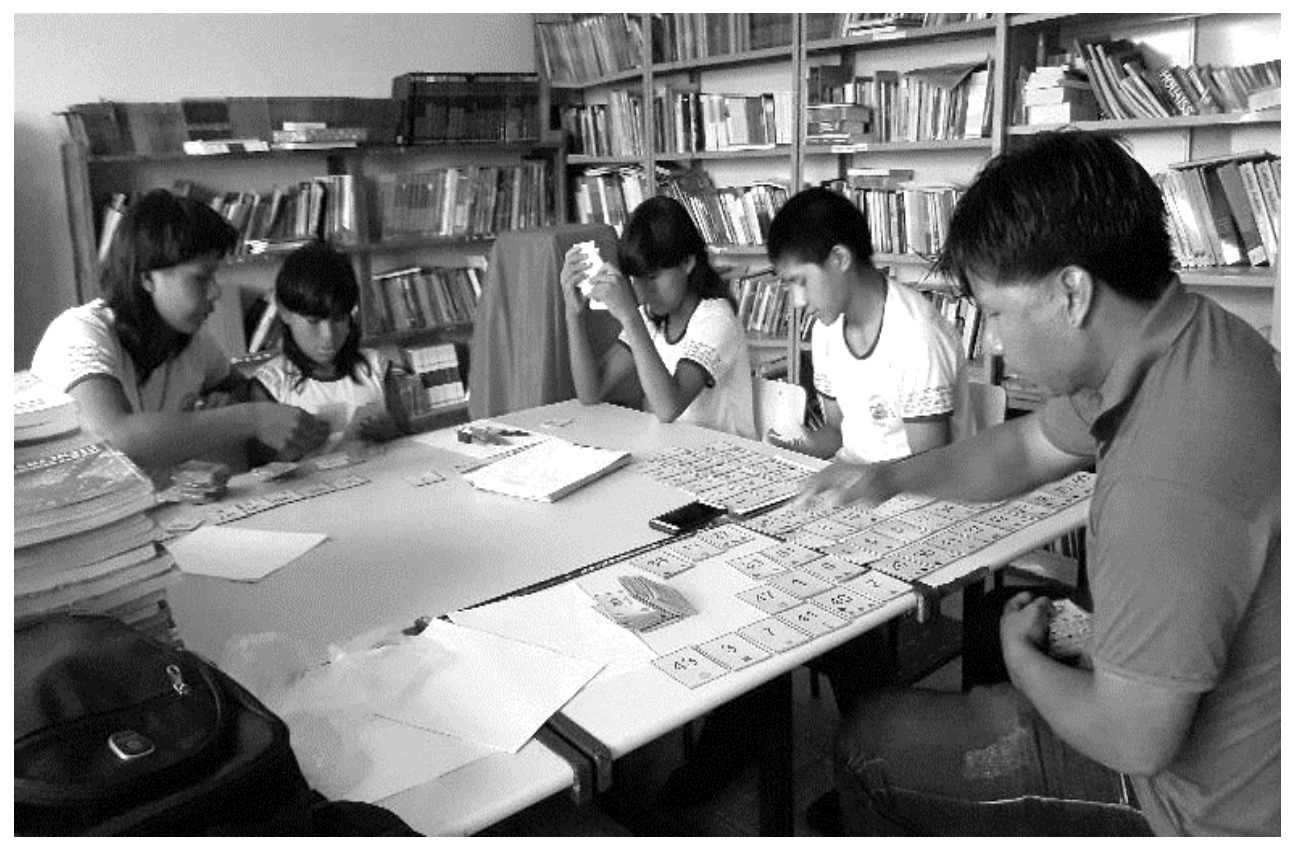

Figura 1 - Registro fotográfico da Oficina "Em busca do segredo" Fonte: Arquivo Pessoal (2018). 
De início, pedi para que formassem duplas para analisar o material, cada dupla receberam um baralho composto por 100 cartas. O objetivo era que os alunos encontrassem o "segredo dos números" dispostos nas cartas. Depois de alguns minutos, fiz algumas perguntas e, como não me responderam, questionei novamente: "Vejam, esses baralhos têm figuras! para que será que elas servem?”.

Os alunos, então, começaram a reparar nas figuras de cada carta, mas o "segredo" ainda não tinha sido encontrado. Posteriormente, peguei as cartas e iniciamos um diálogo:

- "Olha a carta do baralho de número 2, que figura tem nela?"

- "Triângulo."

- "E no baralho de número 3?

- "Quadrado."

- "No número 4?"

- "Dois triângulos."

- "Mas, o que está acontecendo para dois triângulos valer quatro?"

- "Soma." (apenas um dos educandos respondeu).

- "Verdade $2+2=4$, mas vamos olhar a carta de número 6, nela está contido um triângulo que vale dois e um quadrado que vale três, e agora a soma das figuras daria cinco, mas o que está acontecendo pra dar seis?”
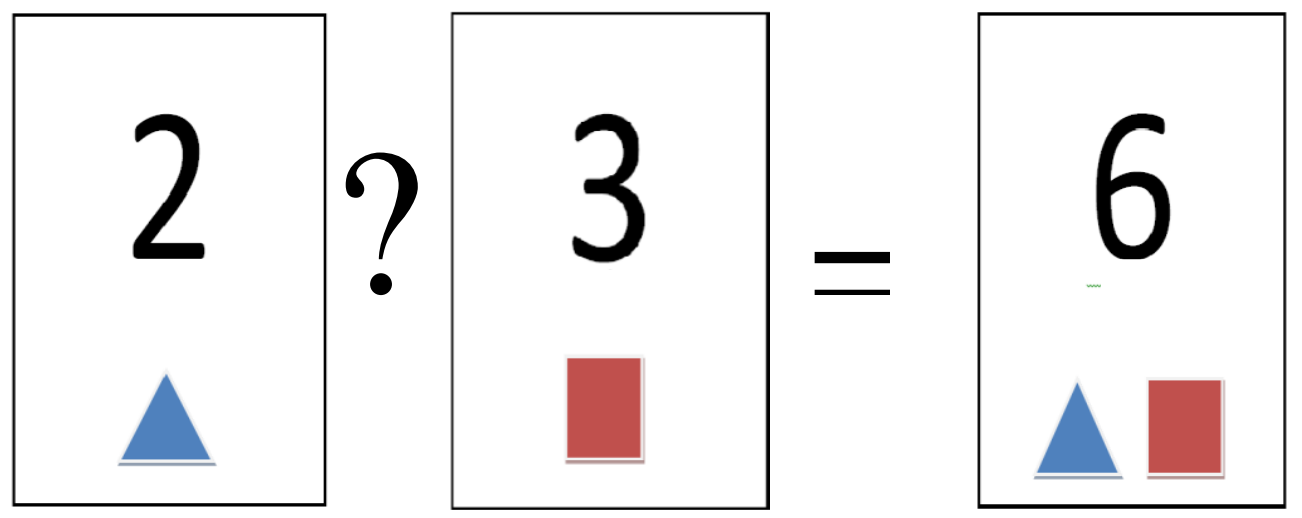

Figura 2 - Cartas do jogo "O segredo dos números" Fonte: Brehm (2015). 
O papel do intérprete indígena na aprendizagem da Matemática Escolar

De súbito, um deles me olhou e tentou falar, mas, ficou nervoso, e se calou. Percebi que ele tinha entendido o que estava acontecendo, mas por nervosismo, desistiu de falar. Continuei com a pergunta, peguei a carta de número quatorze e disse: "o quatorze é representado por um coração que é o sete e um triângulo que é o dois, se somar o total dánove, por que, então, no baralho o resultado é quatorze?"

Então, aquele mesmo educando que não teve coragem de falar anteriormente respondeu: - "Multiplicação." Avaliei que ele não sabia expressar o que é a multiplicação (não sabia enunciar formalmente), mas tinha a noção de como este jogo funcionava e ele conseguiu verificar isto através do baralho.

Em seguida, questionei sobre a divisão. Primeiro, expliquei o conceito do que é divisão, dando exemplo do pirulito que, se eu tiver 5 pirulitos e vou dividir com vocês com quanto pirulitos vou ficar: - "com um", disse um deles. Vocês viram que foi uma divisão exata todos ficaram um pirulito. "Agora, vamos olhar na carta baralho de número quatro qual número eu posso dividir por quatro que dar uma divisão exata?"

Como não conseguiram enxergar as respostas perguntei: quais eram os números que formavam o número quatro; eles sabiam que o triângulo representava o número dois, então, dois foi a única resposta que obtive. Perguntei se o número um estava presente no baralho e eles ficaram em dúvida, disseram que estava, pois qual é a figura do número um como na multiplicação? 0 número 1 é o elemento neutro e, por esse motivo, ele não contém figura.

Ao final da atividade, os educandos me surpreenderam, pois, naquele momento, eles mostraram que estavam preparados e confiantes para qualquer questionamento que eu apresentasse sobre o assunto. Por fim, quando voltaram para sala, perguntei a professora intérprete presente a impressão que ela teve domaterial e da reação dos educandos manipulando as cartas. Sua resposta foi: "Bom, achei que despertou interesse neles, vi que eles estavam entendendo o que você falou. Eu auxilio o educando A e ele nunca responde e hoje ele estava te respondendo ou tentava responder. Achei bom o material, achei que ajudou bastante." 
O papel do intérprete indígena na aprendizagem da Matemática Escolar

\subsection{Considerações sobre a Atividade: segunda etapa}

Na primeira etapa da pesquisa (OLIVEIRA, 2019), busquei compreender como o uso de um material manipulado específico poderia ajudar os educandos indígenas na disciplina de Matemática. Durante a oficina pude observar que os alunos indígenas, com o uso do material, mudaram o comportamento como educandos dentro da sala de aula, estavam conseguindo me responder e se expressar também. Conclui que o material manipulável possibilitou um processo de aprendizagem mais claro e intuitivo para os alunos. Ou seja, a análise permitiu inferir que as respostas demonstraram certo potencial dessa ferramenta na aprendizagem dos educandos indígenas.

A primeira etapa, de algum modo, evidenciou o potencial deste instrumento na aprendizagem dos indígenas, fato que justifica a necessidade de refletir de modo mais aprofundado sobre o uso de materiais manipuláveis na Educação Indígena, bem como sobre algumas indagações que surgiram durante os estudos de fundamentação e na execução da atividade, mas que não foram devidamente exploradas na ocasião. São questões que, de um modo geral, justificam a segunda etapa do estudo.

A partir do que foi desenvolvido, pode-se inferir que os objetivos desta etapa se traduzem na perspectiva de uma reflexão sobre: a) quem são os educandos indígenas?; b) quem são os educadores indígenas, como é seu trabalho e como a presença deles interfere no ensino-aprendizagem dos educandos, especialmente no ensino da matemática?; c) como os materiais manipuláveis, como ferramenta de aprendizagem podem contribuir na aprendizagem desses educandos?; d) como eles - os educandos indígenas - acompanham o desenvolvimento da turma, especialmente no diz respeito à linguagem da matemática escolar?

Ao concluir a revisão e a síntese da primeira etapa, pude perceber que, no transcorrer do estudo, afloraram algumas questões que, de algum modo, justificam a proposta de uma reflexão mais aprofundada das mesmas. Para isso, foram utilizados recursos e instrumentos da análise qualitativa e da Fenomenologia de Edmund Husserl (1859-1938). Um método de análise que não é dedutivo nem empírico, pois ele "consiste em mostrar um dado e esclarecer este mesmo dado. Ela não explica situações mediante leis nem deduz a partir de princípios, mas considera o que está pre- 
O papel do intérprete indígena na aprendizagem da Matemática Escolar

sente a consciência aquilo que é sabido, posto em dúvida, amado, odiado etc." (GIL, 1946, p. 33).

Ainda sobre fenomenologia o autor afirma que por ela se estuda a essência das coisas e como elas são percebidas no mundo. Portanto, não só os objetos da consciência, mas também os próprios atos conscientes, sejam eles intelectivos, volitivos ou afetivos. Concluindo a descrição recorremos a Tripicchio (2008), pois ele reafirma para Husserl, este fenômeno se entende como:

1) A vivência concreta da intuição (o ter presente ou representado, intuitivamente, certo objeto);

2) 0 objeto intuído (aparente), como o que nos aparece aqui e agora.

3) Os "elementos reais" do fenômeno no primeiro sentido, no sentido do ato concreto de aparição ou de intuição. (...) Fenomenologia quer dizer a teoria das vivências em geral e, contidos nelas, de todos os dados, não só reais, senão também intencionais, que podem mostrar-se com evidência nas vivências.

Tendo em vista tais fundamentos, acredito que seja possível uma incursão maior sobre os questionamentos que surgiram a partir da imersão nas leituras de fundamentação e nas reflexões acerca da primeira etapa do estudo. Neste sentido, a primeira indagação aflorada diz respeito a: quem são os educandos indígenas das escolas de Aragarças? A resposta se respalda nos diálogos com os educadores indígenas, com os quais mantive contato. Eles são crianças e jovens que vieram das comunidades indígenas em busca de uma formação que possa contribuir com seu desenvolvimento pessoal e também da comunidade de onde vieram. Portanto, segundo os educadores indígenas, os jovens vêm em busca de um ensino de qualidade, tendo em vista que não estão sendo atendidos como deveriam na própria comunidade.

Complementarmente, refletir sobre eles, me faz concluir que, historicamente, a Educação Escolar Indígena, deve ser considerada um avanço, mas os projetos educacionais desenvolvidos, ao longo desses quinhentos anos, não têm atingido seu objetivo maior, há avanços e conquistas, como é caso da educação diferenciada, mas, durante estes percursos, apareceram muitos obstáculos que me fazem pensar que 
O papel do intérprete indígena na aprendizagem da Matemática Escolar

todo o processo visa atender muito mais a demandas externas que ao próprio indígena.

Pude constatar também que eles se mostram tímidos e inseguros na sala de aula, pois, ao chegar às escolas urbanas, eles passam por uma fase de adaptação, sendo oferecidas aulas em turno de acompanhamento. Registra-se que, durante muito tempo, eles iam para escolas somente para copiar no caderno o que os professores passavam no quadro. Após tantas lutas em busca de um ensino que atendesse suas necessidades, hoje, as escolas estaduais do estado de Goiás incorporaram, ainda que precariamente, os Educadores Intérpretes Indígenas, para auxiliarem os professores em sala de aula.

Outra indagação aflorada diz respeito às questões: quem são os educadores indígenas? A presença e o trabalho deles interferem no ensino e aprendizagem dos educandos, especialmente no ensino da Matemática?

Os Educadores Intérpretes são membros das comunidades indígenas da região, que fazem parte do projeto (uma demanda não regulamentada), que auxilia no letramento dos educandos mesmo não sendo licenciados. São parentes próximos, amigos ou vizinhos da mesma etnia e do mesmo clã dos educandos que estão cursando ou possuem graduação. Eles atuam em sala na tradução dos textos e das falas para a língua materna e vice-versa além de ajudar nas dúvidas das crianças.Mas, é possível dizer, com base no que vivenciei, que a presença deles vai muito além das traduções e das dúvidas retiradas; por já terem passado pelo processo de escolarização, são vistos pelos educandos como referência para continuarem estudando.

Ainda sobre o papel dos Educadores Intérpretes, é sabido que são ativos na busca de melhoria para os indígenas. Eles estão sempre prontos para participar de projetos e trabalhos que possam ajudar no ensino-aprendizagem e na integração social das crianças e jovens. Um exemplo é a professora Tsitedze, quando diz: "é isso que precisamos, ver enxergar o que está acontecendo ou ainda diz: eu auxilio o educando A e ele nunca responde e hoje ele estava te respondendo ou tentava responder". Esta declaração evidencia que os educadores intérpretes têm o importante papel de mediadores entre os dois saberes - cultural e escolar - e entre educador e educando, minimizando as barreiras impostas pela língua e pelo racismo. 
O papel do intérprete indígena na aprendizagem da Matemática Escolar

Mais especificamente, em relação ao ensino de Matemática, os Educadores Intérpretes ainda têm muitas dificuldades. Eles estão a par de vários conteúdos, pois aprenderamna época de suas formações. Contudo, há determinados tópicos que eles precisam do auxílio dos educadores regentes para traduzir para os educandos.É possível que estas dificuldades que possuem sejam decorrentes do fato de eles não terem o estudo mais aprofundado da disciplina de Matemática.

Concluindo, não restam dúvidas quanto à importância desse personagem na escolarização dos indígenas, mas, por outro lado, entendo que, por mais que sejam ativistas, estes educadores precisam compreender as técnicas para o ensino da Matemática.

Quanto à indagação: os materiais manipuláveis, enquanto ferramenta na aprendizagem desses educandos, são efetivos?

A ideia de usar os materiais manipuláveis surgiu das minhas vivências em sala, ao perceber a diversidade cultural que hoje compõe as escolas regulares. Percebi que não ia conseguir ministrar uma aula que abrangesse um conhecimento a todos educandos, pois, na primeira aula, tive contato com todos os estudantes e alguns deles não me compreendiam. Ao perceber que não me entendiam, tive a sensação que, de certo modo, eu os estava excluindo e os impedindo de apreender os conteúdos que tinha planejado para desenvolver com a turma.

Motivada pela busca de estratégias e ferramentas de ensino que incluíssem todos, resolvi levar um material que já havia utilizado durante minha graduação. Pois, para utilizar um material concreto em sala de aula, era preciso formar duplas ou grupos e que respeitasse a cultura de cada um. No momento que os grupos foram formados, já tive a sensação que os educandos indígenas, aos poucos, estavam se incluindo na aprendizagem.

Os materiais concretos possibilitaram o diálogo entre os educandos, com o auxílio dos educadores intérpretes, evidenciando que eles estavam conseguindo socializar com alguém não-indígena, em busca de encontrar o "segredo" do material. Além dessa socialização, o material permitiu a visualização da construção dos núme- 
O papel do intérprete indígena na aprendizagem da Matemática Escolar

ros - esta construção só era vista quando os alunos abstraiam a imagem do número dois (2) do concreto, no baralho, para abstrato nas figuras.

Com o depoimento da intérprete indígena criei uma oficina só para educandos indígenas, pois queria testar a eficácia dessa ferramenta. No decorrer da oficina, os alunos indígenas chegaram sozinhos ao conceito de multiplicação. Logo verifiqueio potencial do material, pois eles conseguiram perceber a transposição do concreto para o abstrato assim construíam um conhecimento de como os números estavam se formando.

Ao refletir sobre o depoimento da principal interlocutora do processo, a professora Tsitedze mostrou que o uso desse material é um ganho importante na aprendizagem deles. Acredito que o Ser indígena, em seu ambiente natural, aprende manipulando as coisas no cotidiano e é exatamente esse o papel do material manipulado no ensino de Matemática.

Ao considerar a declaração da professora intérprete: "Eu auxilio o educando $\mathrm{A}$ e ele nunca responde e hoje ele estava te respondendo ou tentava responder", percebe-se que ela notou uma mudança na desenvoltura dos educandos. Visto que, de algum modo, eles se tornaram mais ativos no processo, ganharam autonomia e segurança para conversar para se expressar.

\section{Considerações finais}

Quero iniciar minhas considerações pelo Estágio Supervisionado, pois foi nesse período que tive o primeiro contato com a realidade escolar. Assim, ao observar a realidade, percebi algumas coisas da prática docente que acontecem cotidianamente, mas que poucas pessoas conhecem. Percebi que a lida não é fácil, os educadores têm metas a cumprir na semana que, às vezes, são interrompidas, têm que planejar todos os dias aulas que não são reconhecidas como importantes para os educandos e, até mesmo, pela sociedade. Realidade que me fez questionar várias vezes se é isto que eu quero para minha vida.

Durante a regência, passei por momentos difíceis, não estava conseguindo colocar em prática o que havia aprendido na Universidade. Somos habituados a plane- 
O papel do intérprete indígena na aprendizagem da Matemática Escolar

jar aulas com metodologias diferentes e, na realidade, nem sempre é possível, uma vez que existem turmas, nas quais as coisas dão certo e, outras, que não. Também existem obstáculos como a indisponibilidade de recursos didáticos tecnológicos e a falta de materiais manipuláveis, entre outros. E, foi durante esse contato com a realidade escolar, que percebi que a graduação é fundamental para um despertar das perspectivas metodológicas para ensino, mas é a prática traz experiências concretas.

Foi na convivência com a prática que percebi a presença dos educandos indígenas nas escolas urbanas. Este é mais um bom exemplo dos desafios para alguns educadores, pois, como planejar uma aula para estes educandos sem apoio da escola e do corpo docente e mesmo do Estado na elaboração desses materiais? Foi pensando nesta nova realidade que busquei estudar sobre a Educação Escolar Indígena, para compreender os motivos que estão os levando a buscar o ensino nas escolas urbanas.

Hoje, após tantas lutas, os indígenas e as escolas de Aragarças contam com o apoio dos professores intérpretes indígenas, mas vejo que isso não é o suficiente. Ao ter presenciado o descaso com estes alunos em sala, fui motivada a buscar compreender por meio da Etnomatemática, da Educação Matemática Crítica e dos Materiais Manipuláveis, maneiras que poderiam melhorar o ensino para estes educandos e que atendessem às necessidades não só deles, mas também dos demais.

Essa realidade, proporcionada pelo estágio, me levou ao desenvolvimento deste estudo, o qual proporcionou grande aprendizado, tanto sobre aspectos da cultura do povo indígena, quanto na busca de possibilidades de ensino que trazem aprendizagem ativas, sobre o quanto desafiadora é a rotina de um(a) professor(a), que sempre tem que estar em busca de conhecimentos para desenvolver uma aula que transmitam valores e que formem cidadãos críticos, conscientes e aptos a lidar com a cidadania, numa perspectiva solidarista. 
O papel do intérprete indígena na aprendizagem da Matemática Escolar

\section{Referências}

BRASIL. Decreto n. 6861, de 27 de maio de 2009. Dispõe sobre a Educação Escolar Indígena, define sua organização em territórios etnoeducacionais, e dá outras providências

Disponível em: http://www.planalto.gov.br/ccivil_03/_Ato2007-2010/2009/Decreto/D6861.htm. Acesso em: 20 de jun. 2019.

BRASIL. [Constituição (1988)]. Constituição da República Federativa do Brasil: promulgada em 5 de outubro de 1988.

Disponível em: http://www.planalto.gov.br/ccivil_03/constituicao/constituicao.htm. Acesso em: 20 de jun. 2019.

BREHM, Junior dos Santos. Múltiplo e Divisores de números naturais um estudo no quinto ano do Ensino Fundamental. 2015. 152f. Dissertação (Mestrado Profissional em Ensino de Matemática) - Instituto de Matemática, Universidade Federal do Rio Grande do Sul, Porto Alegre. 2015.

COSTA, Wanderleya N. G. A etnomatemática da alma A'uwe-xavante em suas relações com mitos. 2007. 268f. Tese (Doutorado em Educação) - Universidade de São Paulo, São Paulo, 2007.

Disponível em: http://www2.fe.usp.br/ etnomat/teses/etnomatemtica-alma-auwe-xavante.pdf, Acesso em: 26 maio 2019.

D'AMBROSIO, Ubirantan. Etnomatemática - Elo entre as tradições e a modernidade. Belo Horizonte: Autêntica, 2016.

GILL, Antônio Carlos. Métodos e técnicas de pesquisa social. 3. ed. São Paulo: Atlas, 1991.

FERREIRA, Mariana Kawai Leal. A educação escolar indígena: um diagnóstico crítico da situação no Brasil. In: SILVA, Aracy Lopes da; LEAL FERREIRA, Mariana Kawai. (Orgs.). Antropologia, História e Educação: a questão indígena e a escola. São Paulo: Global, 2001. p. 71111.

LULA, S. L. I.; GENRO, T.; HADDAD, F. Câmara dos Deputados. Brasília, 2009. Disponível em: http://www2.camara.leg.br/legin/fed/decret/2009/decreto-6861-27-maio-2009-588516publicacaooriginal-113090-pe.html. Acesso em: 20 set. 2018.

OLIVEIRA, Karynna S. O Lúdico, os Índios e a Educação Matemática. ENCONTRO NACIONAL DE EDUCAÇÃO MATEMÁTICA, 13.. 2019, Cuiabá. Anais... (no prelo). 
O papel do intérprete indígena na aprendizagem da Matemática Escolar

PASSOS, Caroline Mendes dos. Etnomatemática e educação matemática crítica: conexões teóricas e práticas. 2008. 153f. Dissertação (em Educação) - Faculdade de Educação, Universidade Federal de Minas Gerais, Belo Horizonte,. 2008.

Disponível em: https://www.ime.usp.br/ brolezzi/carolinepassos.pdf. Acesso em: 20 jul. 2019.

PONTE, João Pedro da. O Desenvolvimento Profissional do Professor de Matemática. Educação e Matemática, Lisboa, n. 31, p. 9-12, 1994.

Disponível em: http://www.educ.fc.ul.pt/docentes/iponte/docs-pt/94-Ponte(Educ\&Mat).rtf. Acesso em: 20 de jun. 2019.

SILVA, A. A. Alguns aspectos do sistema de contagem A'UWẼ/XAVANTE - outros saberes, outros conhecimentos, outras soluções. CONGRESSO BRASILEIRO DE ETNOMATEMÁTICA, 4., 2012, Belém do Pará. Anais... Belém: SBEM-PA, 2012.

Disponível em: http://www.cbem4.ufpa.br/anais/Arquivos/CC ADAILTONSILVA.pdf. Acesso em: 20 de jun. 2019.

SKOVSMOSE, O. Desafios da reflexão em educação matemática crítica. Campinas: Papirus Editora, 2008.

SOUZA, V. C. S. Intérpretes da língua indígena nas escolas regulares do Estado de Goiás 2015 A 2017. 2017. 64f. Monografia - Faculdade de Ciências Sociais, Universidade Federal de Goiás, Goiânia, 2017.

Disponível em: https://www.cienciassociais.ufg.br/up/106/o/Monografia_-

Val\%C3\%A9ria_Cavalcante_da_Silva_Souza.pdf. Acesso em: 29 de jul. 2019.

Artigo recebido em: 31 out. 2019

Aprovado em: 20 nov. 2019 